\title{
RECEITAS A SEREM SEGUIDAS? UMA ANÁLISE DO TERMO EMPREENDEDORISMO DE PALCO ATRAVÉS DE REPORTAGENS DA WEB
}

Lauriene Teixeira Santos ${ }^{1}$ Juliana De Oliveira Becheri ${ }^{1}$ Izadora Ribeiro E Garcia De Oliveira ${ }^{1}$

Paulo Henrique Montagnana Vicente Leme ${ }^{1}$

${ }^{1}$ Universidade Federal de Lavras / Departamento de Administração e Economia 


\section{RECEITAS A SEREM SEGUIDAS? UMA ANÁLISE DO TERMO EMPREENDEDORISMO DE PALCO ATRAVÉS DE REPORTAGENS DA WEB}

Resumo: Considerando que o empreendedorismo é uma área de conhecimento e que o fenômeno "empreendedorismo de palco" tem, ao longo dos últimos anos, ganhado espaço no mundo dos negócios, o objetivo geral do presente artigo é mapear através de reportagens divulgadas na internet, o que tem sido abordado sobre este fenômeno. Espera-se que ao analisar o conteúdo dessas reportagens, seja possível obter dados relevantes para fomentar uma discussão a respeito dessa temática. $\mathrm{O}$ estudo apresenta uma abordagem qualitativa e exploratória. Como técnica de análise dos dados, utilizou-se a análise de conteúdo, sob os preceitos de Bardin. Após a análise das reportagens, como principal resultado obteve-se que a abordagem das reportagens está voltada para um alerta aos leitores sobre o conteúdo difundido do empreendedorismo, mostrando muitas vezes que há grande apelo motivacional, em detrimento de conceitos e práticas e com embasamento teórico/científico.

Palavras-chave: Empreendedorismo. Empreendedorismo de palco. Reportagens da web. Conteúdo motivacional.

\section{$1 \quad$ Introdução}

O tema "empreendedorismo" e seus elementos vêm se tornando aceitos como o fundamental eixo do crescimento econômico e da formação de emprego e renda da época atual (BARROS; PASSOS, 2000; CHANLAT, 1995). A maioria dos autores concorda que o empreendedorismo é sobre fazer as coisas de maneira diferente ou não rotineira, tipicamente desenvolvendo um empreendimento (KATZ; GARTNER, 1985) com o objetivo de obter lucro (KIRZNER, 1973). Alguns assumem uma postura inclusiva e estendem o empreendedorismo a organizações sem fins lucrativos e desenvolvimento cultural (por exemplo, Steyaert e Katz, 2004).

Na visão de Tonelli, Brito e Zambalde (2011) o empreendedorismo é um tema promissor, que se encontra em plena ascensão. Assim, há estudos sobre essa temática nas mais diversas áreas científicas, onde recorrentemente se encontra como objetivo comum, abordar o empreendedorismo e seu impacto em dinâmicas distintas da sociedade (TONELLI; BRITO; ZAMBALDE, 2011).

Todavia, não é apenas no campo científico que o empreendedorismo tem despertado interesse. A mídia de negócios tem voltado sua atenção para o tema, procurando compreender quem seria o empreendedor e como esse fenômeno ajuda a potencializar carreiras (COSTA; BARROS; MARTINS, 2012). Segundo os autores, foi possível perceber nos últimos anos um aumento considerável neste segmento, onde livros, revistas e afins podem, atualmente, serem considerados entre os mais vendidos e populares.

É preciso ressaltar, que esse tipo de discurso nunca esteve vinculado estritamente à área teórica (CARVALHO; CARVALHO; BEZERRA, 2010). Assim, para os autores, há uma abertura para que se despreze o conhecimento originado na academia, com a intenção de que este ramo adquirisse o status de setor de negócios. 
Se de um lado existe a mídia de negócios, buscando vender os discursos contidos em seus aparatos, na outra ponta, encontram-se profissionais inseridos dentro de um mercado de trabalho exigente e mutável, que passa constante por enxugamentos demissões e terceirizações (CARVALHO; CARVALHO; BEZERRA, 2010). Assim, há uma impressão permanente de que todo conhecimento está fadado a ficar desatualizado, principalmente na área de negócios e um mundo globalizado (CARVALHO; CARVALHO; BEZERRA, 2010).

Neste contexto surge o empreendedorismo de palco, onde pessoas com boa oratória cativam o público, sob a pretensão de agregar novos conhecimentos, porém, em grande parte dos casos, sem possuir uma vivência profissional e não agregando nada além de frases de efeito e ideias vazias (SANTOS; FREITAS, 2017).

Entende-se que todo esse processo pode adquirir contornos ideológicos quando é inserido em um contexto em que há uma valorização de "receitas prontas", contribuindo então para que haja uma homogeneização de conceitos e práticas, além da propagação da imagem de profissionais idealizados (COSTA; BARROS; MARTINS, 2012). Assim, surge o tipo ideal do empreendedor, como sendo um herói emblemático, que se atreve a enveredar por novos caminhos (COSTA; BARROS; MARTINS, 2012).

Assim, é possível dizer que ao tratar o empreendedorismo com esse enfoque, essas leituras e 'discursos' se alinham mais com a perspectiva subjetivista do empreendedorismo. Essa perspectiva foca na figura do indivíduo empreendedor, bem como, em sua atuação, suas habilidades, suas capacidades e a construção de sua identidade (TONELLI; BRITO; ZAMBALDE, 2011).

Dessa forma, o objetivo geral do presente artigo é mapear através de reportagens divulgadas na internet, o que tem sido abordado sobre o fenômeno do "Empreendedorismo de Palco". Justifica-se a realização do presente estudo, visto que o conteúdo de reportagens divulgadas na web é uma poderosa fonte de dados que podem ser convertidos em interessantes e válidas informações (GALVÃO; MARIN, 2009). Além disso, ao considerar o empreendedorismo de palco como um fenômeno, que pode ter sua expressividade aumentada pelo alcance da internet, torna-se relevante entender como isso tem sido tratado em veículos de comunicação de atingem grande parte da população brasileira.

\section{$2 \quad$ Fundamentação teórica}

A fundamentação teórica do presente artigo buscou apresentar, com base em trabalhos publicados anteriormente, sobre o que seria o fenômeno 'empreendedorismo de palco'.

\subsection{Empreendedorismo de palco}

Para que seja possível iniciar uma discussão sobre 'empreendedorismo de palco' se faz necessário buscar algumas causas que apontem para o surgimento de tal fenômeno. Nesse sentido, Dias e Wetzel (2010) indicam que épocas em que há o aumento do desemprego, são também épocas capazes de impulsionar o indivíduo a criar novas possibilidades de sobrevivência, e ao fazer isso, a partir de ideias inovadoras e inventivas, podem alavancar a economia de um país.

No Brasil, de acordo com dados do Instituto de Pesquisa Econômica Aplicada - IPEA (2019) o mercado de trabalho segue bastante deteriorado, permeado por altos contingentes de 
desocupados, desalentados e subocupados (LAMEIRAS et al., 2019). E é essa conjuntura de incertezas e mudanças, bem como, as exigências feitas a todas as pessoas que se encontram no mercado de trabalho ou à procura de ingressar nele, tem gerado uma grande ansiedade para que o indivíduo se mantenha funcional e apto ao mercado (WOOD JR.; PAULA, 2001).

Assim, diante da situação econômica e do mercado de trabalho do país, os benefícios advindos do empreendedorismo tornaram-se bastante difundidos por diversas agências, além dos programas de incentivos governamentais (DIAS; WETZEL, 2010). Dessa forma, de acordo com os autores mencionados, são exaltadas as iniciativas particulares de cada pessoa na busca de abrir um negócio, ou a dedicação a qualquer atividade autônoma que lhe possibilite ser "patrão de si mesmo".

Todo o contexto de turbulência e competição contribuiu, então, para uma geração de literatura orientada para questões voltadas às ansiedades e dilemas característicos dos profissionais de administração: uma literatura de pop-management, na qual o conteúdo perpassa por alguns padrões, como relatos de feitos heroicos, exaltação de novas tecnologias gerenciais e conselhos para que as pessoas alcancem sucesso profissional (WOOD JR.; PAULA, 2006). Outro aspecto abordado na literatura do management está na apresentação do empreendedorismo como comportamento e atitude pessoal, que deve extrapolar o mercado de trabalho e atingir outras esferas sociais (DIAS; WETZEL, 2010).

"Atordoados pelas exigências e pela velocidade em que tudo parece mudar, os indivíduos, assim como as organizações, também buscam referências que possam conduzi-los com segurança ao êxito" (WOOD JR.; PAULA, 2001, p. 8). Assim, há uma concepção de que o empreendedorismo pode ajudar a sanar diversos problemas atuais, do desemprego à infelicidade, passando pela crise de valores, onde tudo pode ser solucionado diante da prática empreendedora, que busca combinar plano de negócios, psicologia positiva e inspiração (CASAQUI, 2017).

Todavia, essas narrativas são empregadas como autoajuda, tendo em grande parte dos casos, a intenção de orientar as pessoas sobre uma forma mais acertada de enfrentar as dificuldades que se apresentam e alcançar sucesso (MOTTA; CORÁ; MENDES, 2019). Dessa forma, de acordo com Duarte e Medeiros (2016) nas organizações, as histórias e fantasias de heroísmo estão cada vez mais comuns, servindo como uma válvula de escape para aliviar tensões, enquanto serve de guia para que decisões sejam tomadas em carreiras voltadas para a área dos negócios.

O culto ao empreendedorismo surge em um contexto onde há uma grande valorização de receitas prontas oferecidas pelo mercado de soluções gerenciais, criando assim um novo imaginário (WOOD JR.; PAULA, 2001). Assim, na visão de Dias e Wetzel (2010), essas receitas apresentam um determinado tipo de conteúdo, onde há a responsabilização pessoal dos indivíduos por sua situação profissional e financeira, independente se essa situação seja de empregado ou desempregado, de sucesso ou fracasso, ou da sobrevivência e falência de seu negócio.

Segundo Duarte e Medeiros (2016) no decorrer da história, a visão de um homem com deveres foi modificada para um homem que se autorrealiza, sendo assim, responsável por seu próprio caminho e pelo impacto que causa no ambiente em que está inserido. Motta, Corá e Mendes (2019) compartilham dessa visão, e apontam que uma vez que estas receitas estão alinhadas com o modelo tradicional de administração, os profissionais são responsabilizados 
para que busquem atingir alguma meta, de forma que é evidenciado que somente através de um desempenho exemplar de suas atribuições, é que uma trajetória de conquista se apresentará.

Assim, torna-se acessível o conhecimento de características gerencialistas por um amplo público que busca "receitas" prontas, sem buscarem por uma reflexão crítica, para que seja possível construir uma visão emancipada, com diferentes pontos de vista, contradições e conflitos (MOTTA; CORÁ; MENDES, 2019). O empreendedorismo de palco surge através de conselhos, dicas e expressões de efeito que pouco estão atreladas a condições práticas, mas que possuem uma forte carga sentimental, fazendo alusão ao potencial infinito de ação e imaginação que sujeitos engajados devem possuir para se tornarem empreendedores de sucesso (FARIA, 2018).

As ideias difundidas têm ganhado a força de dogma, uma vez que não há grandes questionamentos de sua validade, e há uma forte tendência em acreditar na sua universalidade (WOOD JR.; PAULA, 2001). Dessa forma, por não haver questionamentos, a cultura do empreendedorismo tem apresentado contornos de ideologia, e por essa razão a poucas reflexões sobre suas consequências na vida social, organizacional e pessoal, além de coibir a realização de críticas a respeito do significado de sua hegemonia (WOOD JR.; PAULA, 2001).

O empreendedorismo de palco é hoje uma indústria que mobiliza composto formado por setores do entretenimento, mídia e mercado editorial voltada para comercializar palestras, livros, vivências corporativas e todo tipo de conteúdo motivacional que tem como objetivo fomentar o comportamento empreendedor junto a um público leigo no Brasil (FARIA, 2018, p. 111).

A ideologia do empreendedorismo é difundida a partir dos mais diversos meios de comunicação, indo de palestras veiculadas pela internet a blogs de autoajuda, de empreendimentos sociais a propostas educacionais, dentre outras possibilidades de propagação (CASAQUI, 2017). Uma ferramenta que tem ajudado muito, de forma estratégica, na difusão desses valores são os meios de comunicação em massa, onde a proliferação de mídias particulares tem difundido certa lógica e pacotes gerenciais, popularizando o mundo dos negócios e do management (DIAS; WETZEL, 2010).

Neste ponto, destaca-se o papel da internet como meio de comunicação de difusão desses conceitos. Plataformas como Instagram, Facebook e YouTube, são veículos onde é facilitado o encontro de 'empreendedores' com pessoas dispostas a seguirem seus ensinamentos. Discursos que antes eram restritos a livros e revistas, atualmente conseguem uma enorme abrangência. De acordo com Casaqui (2017, p. 15) "os processos comunicacionais que difundem essa cultura são essenciais no projeto da sociedade empreendedora e seus enquadramentos, suas formas de convocação, suas propostas de engajamento dos indivíduos".

Ao analisar diversos trabalhos a respeito dessa temática, Duarte e Medeiros (2016) entendem que nesses discursos há uma simplificação de conceitos complexos, deixando a entender, muitas vezes de forma errônea, que a partir do esforço empregado os resultados serão positivos. Assim, pode-se dizer que os discursos são alienantes e que precisam ser utilizados com cautela (DUARTE; MEDEIROS, 2016). 


\section{$3 \quad$ Procedimentos metodológicos}

O presente estudo é caracterizado como uma pesquisa qualitativa exploratória. É qualitativa, pois se busca conhecer, através de reportagens publicadas na web, o que tem sido abordado sobre o fenômeno "empreendedorismo de palco". Assim, de acordo com Godoy (1995) a pesquisa qualitativa não possui preocupação em enumerar e/ou medir os eventos estudados, nem conta com procedimentos estatísticos para analisar os dados obtidos. Ainda de acordo com a autora, as questões e os focos de interesse podem se apresentar de uma maneira mais ampla e irem se definindo conforme o estudo é desenvolvido.

É também uma pesquisa exploratória, pois de acordo com o objetivo apresentado, pretende-se investigar esse fenômeno para que se possa compreender melhor sobre ele. Pesquisas exploratórias buscam aprimorar ideias ou descobrir intuições a respeito de determinado fenômeno, de forma que seja possível adquirir mais familiaridade com o problema, com a intenção de fazer com que este se apresente de uma forma mais evidente (GIL, 2002).

Dito isso, para a elaboração da pesquisa, foram selecionados os endereços eletrônicos que contivessem no título ou em seu texto o termo "empreendedorismo de palco". Optou-se por não buscar outros termos, visto que não há sinônimos que possam corresponder exatamente ao fenômeno que se buscou estudar, além de que, entendeu-se que a busca de outros termos poderia comprometer os resultados obtidos.

Para essa seleção, utilizou-se como ferramenta de busca o Google, através de um browser neutro, para que o resultado apresentado não fosse comprometido por buscas anteriores realizadas através dessa mesma ferramenta. Para a realização da busca, foi feito também um recorte temporal, buscando constituir o corpus para análise com as reportagens mais recentes. Dessa forma, foram selecionados os vinte primeiros endereços eletrônicos apresentados pela ferramenta de busca, entre os anos de 2016 a 2019, sendo que estes são classificadas pelo próprio buscador pelo grau de relevância.

Em um primeiro momento, obtiveram-se, então, oitenta endereços eletrônicos que continham o termo "empreendedorismo de palco". Contudo, para uma melhor utilização dos critérios e ferramentas de análise como forma de proporcionar rigor metodológico do trabalho, optou-se somente por trabalhar com as reportagens de blogs ou de sites jornalísticos. Logo, se eliminou da amostra informações sobre o tema que foram publicadas no Twitter, Facebook, podcasts, fóruns de discussão e vídeos do YouTube. Também foram eliminadas reportagens repetidas, pois foi identificado que haviam reportagens repostadas em diferentes endereços eletrônicos e em data posterior a primeira encontrada. Após essa etapa, o número de reportagens foi reduzido para sessenta.

Assim, foi realizada a primeira leitura do material coletado, onde foi possível perceber que algumas das reportagens tratavam de assuntos que não condiziam com o tema da pesquisa, e que por algum motivo, apenas possuíam o termo citado no corpo do texto, sem apresentar maiores aprofundamentos sobre o assunto. Eliminou-se então, as reportagens em que acontecia esse fato, pois não se justificaria a utilização dessas. Posto isso, o número final de reportagens analisadas foi de trinta e quatro. A Tabela 1 apresenta as etapas realizadas para a coleta de dados.

Tabela 1 - Etapas da coleta de dados 


\begin{tabular}{|l|l|}
\hline \multicolumn{1}{|c|}{ Etapas } & \multicolumn{1}{|c|}{ Coleta de dados } \\
\hline Browser de busca & Navegação oculta \\
\hline Ferramenta de busca & Google \\
\hline Termo de busca & "Empreendedorismo de palco" \\
\hline Período de coleta & 01 de janeiro de 2016 a 31 de agosto de 2019 \\
\hline Tabulação & $\begin{array}{l}\text { Título da reportagem, site, autor (se houvesse especificado), } \\
\text { data e link da reportagem }\end{array}$ \\
\hline Endereços selecionados & 80 \\
\hline Após a primeira exclusão & 60 \\
\hline $\begin{array}{l}\text { Após a segunda exclusão (número final de } \\
\text { reportagens analisadas) }\end{array}$ & 34 \\
\hline Categorização dos dados & Categorias emergentes da teoria e dos dados \\
\hline Análise dos dados & Análise de conteúdo \\
\hline
\end{tabular}

Fonte: Elaborado pelas autoras (2019).

Para analisar os dados obtidos utilizou-se a técnica de análise de conteúdo, seguindo os preceitos de Bardin (1979). Dessa forma, dividiu-se a análise em três etapas: (1) préanálise; (2) exploração do material; (3) tratamento dos resultados obtidos e interpretação. $\mathrm{Na}$ fase da pré-análise foi feita uma leitura flutuante das reportagens selecionadas, buscando uma maior interação com o corpus obtido, bem como identificar possíveis categorias emergidas dos dados. Assim, a pesquisa contou com categorias mistas, sendo aquelas que emergem da teoria e dos dados coletados. As categorias de análise foram: definições sobre empreendedorismo de palco; falsas promessas; empreendedorismo como autoajuda; indústria do sonho; voltar o foco para ferramentas concretas.

$\mathrm{Na}$ fase de exploração do material, foram realizados recortes e classificação dos trechos das reportagens considerados importantes para o esclarecimento da temática estudada. Esses trechos foram relacionados a partir das categorias criadas na fase de pré-análise. Em um último momento, foi realizado o tratamento e interpretação dos dados obtidos, onde novamente se fez uma leitura dos trechos alocados dentro de categorias, buscando encontrar relações entre os mesmos, para que fosse possível responder ao objetivo proposto. Destaca-se ainda que a fundamentação teórica foi essencial nesse momento, colaborando na interpretação dos dados.

\section{$4 \quad$ Resultados e discussão}

Para uma melhor apresentação dos resultados obtidos, optou-se por apresentá-los de acordo com as categorias utilizadas na análise: definições sobre empreendedorismo de palco; falsas promessas; empreendedorismo como autoajuda; indústria do sonho; voltar o foco para ferramentas concretas.

\subsection{Definições sobre empreendedorismo de palco}

Ao analisar as reportagens selecionadas para compor este estudo, foi possível perceber que grande parte delas trazia alguma definição do que seria o "empreendedorismo de palco". Assim, apresentam-se abaixo algumas das definições apresentadas. 
Você, como interessado no assunto, já foi em alguma palestra onde o palestrante falou, falou e falou, mas no final das contas não falou nada? Isso é empreendedorismo de palco! [...] A palestra é visualmente bonita, os infinitos slides são todos em um padrão de design invejável e a oratória é impecável, mas ... na hora de fazer o balanço do que foi aprendido, todo aquele momento não acrescentou nada. [...] É muito comum que termos técnicos e estrangeirismos sejam usados neste tipo de evento que beira o espetáculo em forma de palestra, já que eles dão um ar de sofisticação e "profissionalismo" [...] Empreendedorismo de palco não trata de um negócio de sucesso ou não, trata de passar um conteúdo vazio de ideias para as pessoas (SAIA DO LUGAR, 2016).

Este tipo de empreendedorismo se caracteriza por projetos vazios em conteúdo e valor, mas com empreendedores midiáticos que parecem nutrir-se unicamente de uma vaidade sem fim, alimentados pelas redes sociais e por um público ansioso para encontrar exemplos de sucesso rápido (PEQUENAS EMPRESAS, GRANDES NEGÓCIOS, 2016).

O empreendedorismo de palco é a forma como são denominadas palestras e outras ações realizadas para difundir o empreendedorismo, utilizando técnicas fortemente motivacionais e muitas vezes baseadas em "clichês" como "lute pelos seus sonhos" ou "tudo é possível se você acreditar". E, embora esses não sejam conselhos ruins, são frases bastante desgastadas e que muitas vezes não condizem com a realidade e os desafios que é empreender (ADMINISTRADORES, 2017).

Assim, nota-se nos trechos acima, que a definição de empreendedorismo de palco está bastante relacionada com eventos em que há apelos midiáticos, mas onde o conteúdo a ser difundido nem sempre possui embasamento prático ou teórico, utilizando de valores motivacionais para cativar o público. Tudo isso, vai de encontro à definição proposta por Faria (2018), apresentando que o empreendedorismo possui forte apelo motivacional, desenvolvendo essas ideias junto a um público leigo no Brasil.

Considera-se então, que é relevante argumentar sobre a efetividade de tais eventos, palestras e/ou livros, visto que segundo as definições encontradas, os conteúdos divulgados podem ser bastante questionáveis. Com relação a este aspecto Wood Jr. e Paula (2001) destacam a cultura do empreendedorismo tem, ao longo do tempo, apresentado alguns aspectos de ideologia, visto que não há grandes questionamentos a respeitos dos conteúdos veiculados.

Percebe-se também, que através dos trechos das reportagens, os conteúdos apresentados por empreendedores de palco, podem remeter em um sucesso rápido, apresentando discursos que em muitas das vezes, não condizem com a realidade do mercado e com os reais desafios enfrentados por alguém que deseja se tornar um empreendedor. Isso conduz ao próximo tópico, que são as falsas promessas.

\subsection{Falsas promessas}

Com relação ao conteúdo que compõem os eventos, palestras e livros realizados por empreendedores de palco, há um alerta, pois o fenômeno é basicamente definido por não apresentar um conteúdo confiável e manter seu foco na parte motivacional.

Se você está pensando em abrir um negócio ou entrar de vez na economia digital, oferecendo produtos ou serviços, ou até mesmo utilizar a internet como poder complementar a um negócio físico que você já possua, tome cuidado! Há uma 
indústria de falsas promessas e de prosperidade barata, que tentará te capturar $(\mathrm{O}$ NOVO MERCADO, 2016).

Grande parte das reportagens analisadas, ainda que não possuam trechos específicos, possuem esse tom de alerta, buscando revelar para seus leitores que há de se ter certo cuidado com promessas grandes e que asseguram resultados rápidos.

O que é perigoso - e está longe de ser uma característica exclusiva dos empreendedores de palco - são os discursos ingênuos e que incentivam pessoas a assumirem riscos desproporcionais. [...] Instituir a figura do Empreendedor de Palco teve um papel importante para a identificação de um padrão, mas se prender ao estereótipo e não ao discurso problemático ainda deixa pessoas inocentes vulneráveis. O problema não é o palco, mas a superficialidade do que está sendo dito lá em cima (MEDIUM, 2018).

Exatamente neste ponto, também é realizado um alerta sobre a difusão e reprodução de fórmulas prontas, mostrando que esta forma de se apresentar o conteúdo é um dos pilares do empreendedorismo de palco. Segundo Wood Jr. e Paula (2001) atualmente há um contexto de grande valorização de receitas prontas.

Contudo, no lugar de obras de conteúdo didático, vemos best-sellers que prometem fórmulas para a prosperidade e/ou ensinar o passo a passo para alcançar o grande sucesso e lições para ter uma visão tão empreendedora quanto Steve Jobs (ADMINISTRADORES, 2017).

Assim, é importante ressaltar que o objetivo destas palestras se alterou com o passar do tempo e, hoje, muitos palestrantes usam esses eventos para vender livros e apresentar um discurso pronto sobre como atingir o sucesso, estipulando uma fórmula mágica, que não retrata o real caminho trilhado pelos empreendedores (PET ADM UFC, 2017).

O empreendedorismo se resumiu a slideshow. E o motivo é simples: As pessoas compram o que elas querem ouvir. É nesse momento que o empreendedor de palco cresce. $\mathrm{O}$ empreendedorismo de quem, repetindo, nunca empreendeu. Mas sabe te ensinar como conquistar sucesso, fama e dinheiro. E de preferência, rápido, agora! (FÁBRICA 3, 2019).

Assim, cabe questionar se o conteúdo apresentado por empreendedores de palco é realmente relevante e eficaz. Motta, Corá e Mendes (2019) chamam a atenção para este aspecto, quando apontam que apesar de tornar acessível o conhecimento sobre aspectos gerencialistas para um grande público, isso acontece através da busca desse público por "receitas prontas", o que inviabiliza a busca por uma reflexão crítica. Assim, para os autores, não há a construção de uma visão emancipada, onde seja possível que diferentes pontos de vista sejam considerados.

Segundo Dias e Wetzel (2010), essas receitas apresentam também um conteúdo que busca responsabilizar os indivíduos por sua condição profissional e financeira, o que também foi encontrado nas reportagens analisadas.

Quando você tenta seguir as dicas de sucesso do empreendedorismo de palco, você se pega perdido porque parece que o erro é seu, a falha é sua quando o objetivo não é alcançado ou a sua história não trilha o mesmo caminho que o palestrante garantiu durante sua apresentação (MANUAL DO HOMEM MODERNO, 2016). 
O intuito desse post, é desafiar o mito propagado atualmente de que o sucesso e, consequentemente o fracasso, dependem apenas do quanto nos achamos merecedores. Lembrem-se que enquanto o seu empreendedor de palco favorito estava alcançando o sucesso, muito mais gente estava falhando, e isso não quer dizer, necessariamente, que eles foram menos "esforçados" ou merecedores (EU, CEO, 2016).

A palavra de ordem é "deixe de ser medíocre" hostilizando quem deseja levar uma vida de poucas ambições e com o foco em outros valores (MEDIUM, 2018).

Assim, essa visão de responsabilizar o indivíduo por todos os aspectos relacionados ao seu sucesso ou fracasso, se estende para além da esfera de empreendedorismo. Dias e Wetzel (2010) apontam que a responsabilização pessoal acontece tanto para pessoas empregadas ou desempregadas, e para aquelas que exercem atividades autônomas ou possuem um empreendimento regulamentado. As "receitas prontas" difundidas evidenciam que apenas através de um desempenho exemplar é que as conquistas serão alcançadas (MOTTA; CORÁ; MENDES, 2019).

\subsection{Empreendedorismo como autoajuda}

$\mathrm{Na}$ ótica do empreendedorismo de palco, uma das formas de se apresentar e falar sobre o empreendedorismo, está utilizar fortes apelos motivacionais, chegando a se assemelhar com o conteúdo de livros de autoajuda. Segundo Motta, Corá e Mendes (2019) as narrativas apresentam uma intenção de orientar as pessoas sobre uma forma eficaz de lidar com as dificuldades apresentadas, para que estas possam alcançar sucesso, porém, são empregadas como autoajuda.

O discurso de autoajuda, porém, não é escolhido por acaso. Conteúdos motivacionais, que incentivam as pessoas a saírem da sua zona de conforto, fazem muito sucesso e garantem uma legião de fãs aos empreendedores de palco. São cursos, palestras, livros, e-books, posts em redes sociais, presenças em eventos e consultorias que ajudam a movimentar a indústria do empreendedorismo (GAZETA DO POVO, 2016).

A maior crítica ao empreendedorismo de palco é que os conselhos motivacionais e os clichês que apelam para a emoção acabam fazendo com que pessoas inexperientes tenham uma visão equivocada sobre empreendedorismo, entrem no mercado sem nenhum preparo e acabem se tornando números nas estatísticas de falência, o que é muito frustrante e também prejudicial para o cenário empreendedor. [...] Um dos objetivos do empreendedorismo de palco é vender livros, palestras e documentários para auxiliar futuros empreendedores. O problema é quando esse material se limita à autoajuda e oferece pouco ou nenhum conhecimento prático que possa fazer uma real diferença nos negócios (ADMINISTRADORES, 2017).

Muitas vezes, esses profissionais focam mais na parte motivacional do empreendedorismo do que nas ações, podendo fazer com que os alunos consumam muitos conteúdos, porém não cheguem a colocar seus projetos em prática. Isso não significa que você não possa aproveitar nenhuma dica, mas vale ficar atento (SERASA EXPERIAN, 2018).

O problema é que os conteúdos que realmente poderiam ser um oráculo para ajudar alguém a alcançar um objetivo com seu negócio, se tornaram conteúdos de auto 
ajuda - que é o que vende - mas não serão essas palavras de incentivo que ajudarão um empreendedor na prática (SAIA DO LUGAR, 2016).

De acordo com os trechos das reportagens analisadas, apresentados acima, é possível perceber que essa forma de passar os conteúdos, utilizada pelos empreendedores de palco, precisa ser tratada com a devida atenção, já que o conteúdo prático, que poderia ajudar no alcance de resultados palpáveis para as empresas, acaba sendo trocado por palavras de motivação e incentivo.

Isso corrobora com o que Faria (2018) destacou, dizendo que o empreendedorismo de palco se apresenta por meio de conselhos, dicas e expressões de efeitos, que em pouco contribuem para condições práticas. O conteúdo possui uma forte carga sentimental, apresentando que sujeitos engajados, que querem se tornar empreendedores de sucesso, devem ter um potencial infinito de ação e imaginação (FARIA, 2018).

Outro ponto a ser destacado quando se trata do fator motivacional apresentado por empreendedores de palco, de acordo com Duarte e Medeiros (2016) são as histórias e fantasias de heroísmo, onde estas são tratadas como guia para se tomar decisões em carreiras voltadas para a área dos negócios. Assim, são utilizadas histórias de pessoas que obtiveram sucesso, para mostrar que se uma pessoa conseguiu determinado feito, outras também podem conseguir, desconsiderando assim, diversos outros aspectos que vão além da motivação.

\section{4 “Indústria do sonho"}

O empreendedorismo de palco busca, através dos conteúdos difundidos, vender a ideia de uma "indústria do sonho". Assim, o empreendedorismo acaba sendo entendido, como uma forma de solucionar problemas das mais diversas esferas. Além disso, é difundida a noção de que toda a trajetória será encantadora.

A verdade é que o empreendedorismo está virando uma espécie de religião, muitos o veem como a solução para os problemas financeiros, as desavenças com o chefe ou a falta de tempo. Uma visão mais confortável de futuro ou, simplesmente, o único destino possível para alguém tão "brilhante" e destinado ao sucesso total (EU, CEO, 2016).

Esse modelo atrai muitas pessoas que ainda não tiveram uma profunda experiência empreendedora, pois as encanta com um "mundo mágico de sonhos" (ADMINISTRADORES, 2016).

O mundo é dos sonhadores! Mas dos sonhadores com pé no chão, com objetivos viáveis e negócios consistentes. O mundo não é cor de rosa. Quanto mais rápido você cair na real, menos frustrante será sua jornada e maiores serão suas chances de sucesso (RENAN VIEGAS, 2019).

É importante fazer com que o empreendedorismo não se perca no meio dessa fase de glamourização que está acontecendo. É interessante que o assunto tenha ganhado mídia e visibilidade, porém, não se trata de uma vitrine pessoal (SAIA DO LUGAR, 2016).

Como evidenciado pelo autor Casaqui (2017), há uma busca por combinar o plano de negócios com uma psicologia positiva e inspiração, fazendo com que se conceba o empreendedorismo como uma forma de sanar diversos problemas além do desemprego, como crise de valores, infelicidade, dentre outros. Assim, a dedicação de uma pessoa, a qualquer 
atividade autônoma que lhe traga possibilidades de ser "patrão de si mesmo" são exaltadas (DIAS; WETZEL, 2010) como se tudo fosse ser, segundo os trechos supramencionados, um mundo mágico dos sonhos.

\subsection{Voltar o foco para ferramentas concretas}

Por fim, muitas das reportagens analisadas discorriam sobre "empreendedorismo de palco" buscando chamar atenção para que o fato de que empreender requer ferramentas concretas, conhecimento do mercado, dentre diversos outros aspectos. Chama-se a atenção também, para o distanciamento do que é essencial para o empreendedorismo, muito disso por causa do que já foi discutido anteriormente: difusão de "fórmulas prontas", grande foco em aspectos motivacionais e de autoajuda e trabalhar com uma "indústria do sonho".

Talvez a essência do empreendedorismo tenha sido tomada pelo empreendedorismo de palco, soluções teóricas que no final das contas não levam empreendedores a lugar nenhum. Mas a prática é muito importante para ter um empreendimento que tenha resultados de verdade (SAIA DO LUGAR, 2016).

O que vimos até aqui, nos mostra que a dedicação por si só, não é suficiente para o sucesso. Um cenário econômico favorável e novas tecnologias são apenas alguns exemplos de fatores essenciais para que tudo corra bem (EU, CEO, 2016).

Isso leva muito estudo, prática e principalmente, testes. Uma coisa que funciona pro meu negócio pode não funcionar no seu. Não existe um padrão ou fórmula do sucesso absoluto (BLOG MARKETING DIGITAL, 2016).

O empreendedorismo real está ligado com causas efetivas, com vivências mais precisas de realidade, com objetivos de mercado mais sólidos, com experiências plenamente palpáveis. Ele foi feito em repostas a vida inconstante, uma espécie de combate contínuo aos obstáculos, uma luta corajosa diante da contrariedade, como uma guerra aos contratempos. Nada é fácil! (ROCKCONTENT, 2018).

Tem diversos empreendedores de sucessos que estão longe dos holofotes. A fama só aparece pra quem busca por ela e isso não quer dizer necessariamente que esta pessoa é um bom exemplo de empreendedorismo. Pode ser apenas um bom motivador. [...] A verdade é que pra aprender a empreender de verdade você vai precisar conhecer gente comum, que está há anos lutando pra fazer seu negócio dar certo (GUI SANTOS PRÓ, 2019).

É possível perceber que os trechos explicitados buscam apontar a importância de se ater a conceitos que realmente reflete a realidade do empreendedorismo, que possa de fato ajudar as pessoas que se interessam em empreender a obter um norte e os conhecimentos necessários para dar início a sua jornada. Jornada esta que nem sempre dará certo e será completamente exitosa. Ainda é possível perceber nos trechos um destaque para a importância de se conhecer a vivência de empreendedores reais, que possam contribuir efetivamente na idealização, construção e manutenção de uma empresa.

De acordo com Duarte e Medeiros (2016) é preciso compreender que nos discursos há uma simplificação de conceitos complexos, fazendo com que as pessoas entendam, de uma forma errônea, que os resultados positivos acontecerão proporcionalmente ao esforço empregado. Assim, é necessário que esses discursos sejam utilizados com cautela (DUARTE; MEDEIROS, 2016). Apesar de não ter caráter científico, as reportagens que discorrem sobre o "empreendedorismo de palco", entendem que o discurso difundido sobre o 
empreendedorismo é vago e pouco relevante, quando se considera a criação de empreendimentos reais.

\section{$5 \quad$ Considerações finais}

O presente artigo buscou mapear, através de reportagens divulgadas na internet, o que tem sido abordado sobre o fenômeno do "Empreendedorismo de Palco". Assim, foi possível perceber que as reportagens analisadas puderam ser divididas em grandes categorias: definições sobre empreendedorismo de palco, falsas promessas, empreendedorismo como autoajuda, "indústria do sonho" e voltar o foco para ferramentas concretas. Ao realizar essa divisão, identificou-se que o evento "empreendedorismo de palco" era definido e constituído, conforme as reportagens analisadas, por diversos aspectos.

Os textos das reportagens convergem no sentido de despertar o leitor para que compreendam que empreender de fato, vai muito além do conteúdo difundido pelo "empreendedorismo de palco", sejam através de livros, vídeos, palestras, eventos e outros meios de comunicação. Assim, verificou-se que além das definições apresentadas, em grande parte das reportagens havia um tom de alerta, chamando a atenção dos leitores para o conteúdo veiculado através do "empreendedorismo de palco".

Esse conteúdo, de acordo com as reportagens analisadas, deixa de lado dados reais e relevantes, para trabalhar muito mais com a motivação das pessoas, sendo identificada, inclusive, grande semelhança com temáticas voltadas para a autoajuda. Além disso, trabalham com o sonho das pessoas, com a vontade de que tudo dê certo e de que o sucesso seja alcançado. A partir disso, há grandes possibilidades de que falsas promessas aconteçam, já que, o "empreendedorismo de palco" apresenta "receitas prontas", como se ao seguir o que foi prescrito, e com o devido esforço, os objetivos almejados serão alcançados. Com isso, desconsidera diversos aspectos e especificidades de cada pessoa e de cada empreendimento.

Quando se considera a área de saber sobre empreendedorismo, são diversos os autores que se dedicam a realizar pesquisas sérias, buscando identificar diversos aspectos a respeito dessa prática. No entanto, com base no que tem sido divulgado através do "empreendedorismo de palco" é possível que ideias equivocadas estejam sendo passadas a um grande público, sem possuir nenhum embasamento teórico/científico. Tudo isso, pode acabar enfraquecendo o conceito de empreendedorismo, por este ser ligado de uma forma errônea a conteúdos motivacionais. Assim, acredita-se que sejam necessárias pesquisas acadêmicas que busquem desmistificar esses conteúdos, para que o empreendedorismo não seja confundido com tudo que tem sido divulgado e difundido atualmente.

Como contribuições gerenciais, e inclusive sociais, o presente artigo mostra que não se deve fazer confusão sobre o "empreendedorismo real" com as narrativas empregadas pelo "empreendedorismo motivacional" através dos empreendedores de palco. Além do mais, fica evidente que é necessário manter ressalvas quanto ao "empreendedorismo de palco", principalmente por este não se basear fundamentalmente em conceitos e ferramentas desenvolvidas através de pesquisa acadêmica. Como contribuições acadêmicas, o artigo serve como base para que seja considerada uma discussão futura a respeito desses "desvios" do conceito de empreendedorismo, onde seja possível fomentar uma discussão crítica a respeito dessa temática nas esferas socais e gerenciais. 
Por fim, como pesquisa futura, acredita-se que uma pesquisa voltada para analisar o discurso difundido por "empreendedores de palco" seja de grande valia, uma vez que se pode identificar de uma forma mais profunda, se esse discurso corresponde ao que foi abordado nas reportagens aqui analisadas, podendo inclusive, trazer novos aspectos e abordagens para a discussão, como, por exemplo, os impactos de ideologia do empreendedorismo na sociedade moderna.

\section{Referências bibliográficas}

BARDIN, L. Análise de conteúdo. Lisboa: Edições 70, 1979. 229 p.

BARROS, M. J. F.; PASSOS, E. S. Remando a favor da maré: racionalidade instrumental no curso de administração de empresas. Organização e Sociedade, v.7, n.19, p.161-174, 2000.

BRITO, A. M.; PEREIRA, P. S.; LINARD, A. P. Empreendedorismo. Juazeiro do Norte: Instituto Federal de Educação, Ciência e Tecnologia do Ceára - IFCE, 2013.

CARVALHO, J. L. F.; CARVALHO, F. A. A.; BEZERRA, C. O monge, o executivo e o estudante ludibriado: uma análise empírica sobre leitura eficaz entre alunos de administração. Cadernos EBAPE.BR, v. 8, n. 3, p. 535-549, 2010.

CASAQUI, V. Abordagem crítica da cultura da inspiração: produção de narrativas e o ideário da sociedade empreendedora. Revista da Associação Nacional de Programas de PósGraduação em Comunicação, E-compós, Brasília, v. 20, n. 2, 2017.

CHANLAT, J.F. Quais carreiras e para qual sociedade? Revista de Administração de Empresas, v.35, n.6, p.67-75, 1995.

COSTA, A. M. da.; BARROS, D. F.; MARTINS, P. E. M. A alavanca que move o mundo: o discurso da mídia de negócios sobre o capitalismo empreendedor. Cadernos EBAPE.BR, v. 10, n. 2, p. 357-375, 2012.

DIAS, V. T.; WETZEL, U. Empreendedorismo como ideologia: análise do enfoque da revista Exame em dez anos de publicação (1990-99)*. Revista de Ciências Humanas, v. 44, n. 1, p. 97-118, 2010.

DORNELLAS, J. C. A. Empreendedorismo: transformando ideias em negócio. 2 ed. Rio de Janeiro: Elsevier, 2005.

DORNELLAS, J. C. A. Empreendedorismo: transformando ideias em negócios. 3. ed. Rio de Janeiro: Elsevier, 2008.

DRUCKER, P. F. Innovation and entrepreneurship: practice and principles. New York: Harper \& Row, 1985.

DUARTE, M. P. F. C.; MEDEIROS, C. R. de O. Pop-management: sorte ou revés? Análise das lições de autoajuda na orientação de gestores e executivos. Revista Gestão \& Conexões, Vitória, v. 5, n.1, 2016.

FARIA, L. S. P. de. O poder dos sonhos: uma etnografia de empresas startup no Brasil e no Reino Unido. 2018. Tese (Doutorado) - Universidade Federal do Rio Grande do Sul, Porto Alegre, 2018.

GALVÃO, N. D.; MARIN, H. de F. Técnica de mineração de dados: uma revisão da literatura. Acta Paulista de Enfermagem, v. 22, n. 5, p. 686-690, 2009.

GARTNER, W. B. A conceptual framework for describing the phenomenon of new venture creation. Academy of Management Review, v. 10, n. 4, p. 696-706, 1985.

GIL, A. C. Como elaborar projetos de pesquisa. 4. ed. São Paulo: Atlas, 2002. 
GODOY, A. S. Introdução à pesquisa qualitativa e suas possibilidades. Revista de Administração e Empresas, v. 35, n. 2, p. 57-63, Mar/Abr. 1995.

KATZ, J. A. The Chronology and Intellectual Trajectory of american Entrepreneurship Education 1876-1999. Journal of Business Venturing, n.18, p.283-300, 2003.

KIRZNER, I. M. Competition and entrepreneurship. Chicago: University of Chicago Press. 1973.

LAMEIRAS, M. A. P.; CORSEUIL, C. H. L.; RAMOS, L. R. A.; CARVALHO, S. S. de. 2019. Mercado de trabalho. Acesso em 28 Set 2019. Disponível em: http://www.ipea.gov.br/cartadeconjuntura/index.php/tag/taxa-de-desemprego/.

MOTTA, R.; CORÁ, M.; MENDES, S. Suor, superação e a medalha: uma análise do discurso sobre a literatura pop management inspirada no esporte de competição. Revista Brasileira de Estudos Organizacionais, v. 6, n. 1, p. 77-101, 2019.

SANTOS, E. D. da.; FREITAS, E. C da. Imagens de si no discurso: cenografias e ethé discursivos da empreendedora Bel Pesce na Web. Animus-Revista Interamericana de Comunicação Midiática, v. 16, n. 32, 2017.

SAY, Jean-Baptiste. Cours complet d'economie politique pratique. Paris: Chamerot, 2009.

SCHUMPETER, J. A. The theory of economic development. Cambridge, MA: Harvard University Press, 1942.

STEYAERT, C.; KATZ, J. Reclaiming the space of entrepreneurship in society:geographical, discursive and social dimensions. Entrepreneurship \& Regional Development, v. 16, n.3, p.179-196, 2004.

TONELLI, D. F.; BRITO, M. J. de; ZAMBALDE, A. L. Empreendedorismo na ótica da teoria ator-rede: explorando alternativa às perspectivas subjetivista e objetivista. Cadernos

EBAPE.BR, v. 9, p. 586-603, 2011.

WOOD JR, T.; PAULA, A. P. P. de. A mídia especializada e a cultura do management. Organizações \& Sociedade, v. 13, n. 38, p. 91-105, 2006.

WOOD JR, T.; PAULA, A. P. P. de. Pop-Management. In: ENCONTRO NACIONAL DA ANPAD, 25, Campinas, 2001. Anais... Campinas: ANPAD, 2001.

\section{Reportagens da web}

ABRANTES, L. Empreendedorismo de palco: empreender virou uma farsa? Saia do lugar, 2016. Disponível em: https://saiadolugar.com.br/empreendedorismo-de-palco/. Acesso em: 07 Set. 2019.

BÁRCIA, M. Intraempreendedorismo, a importância da "visão de dono" para as organizações e seus colaboradores. Empreendedor, 2019. Disponível em:

https://empreendedor.com.br/noticia/intraempreendedorismo-a-importancia-da-visao-de-donopara-as-organizacoes-e-seus-colaboradores/. Acesso em: 07 Set. 2019.

BLOG DE MARKETING DIGITAL. Sobre empreendedores de palco, gurus e algumas verdades inconvenientes. Blog de Marketing Digital, 2016. Disponível em:

https://blogdemarketingdigital.com.br/sobre-empreendedores-de-palco-gurus-e-algumasverdades-inconvenientes/. Acesso em: 07 Set. 2019.

BRASIL, S. No empreendedorismo de palco, seja artista de rua. Lidérica, 2018. Disponível em: https://liderica.com.br/no-empreendedorismo-de-palco-seja-artista-de-rua/. Acesso em: 07 Set. 2019. 
CARVALHO, I. de. Por que a indústria do empreendedorismo de palco irá destruir você. O novo mercado, 2016. Disponível em: https://medium.com/o-novo-mercado/porque-aind\%C3\%BAstria-do-empreendedorismo-de-palco-ir\%C3\%A1-destruir-voc\%C3\%AA3e18309ab47f. Acesso em: 07 Set. 2019.

CAVALCANTE, A. Empreendedorismo de palco x empreendedorismo pé no chão. Administradores, 2016. Disponível em: https://administradores.com.br/artigos/empreendedorismo-de-palco-x-empreendedorismo-peno-chao. Acesso em: 07 Set. 2019.

CONFORT, M. Por que você deve ter cuidado com o empreendedorismo de palco. Manual do Homem Moderno, 2016. Disponível em:

https://manualdohomemmoderno.com.br/comportamento/por-que-voce-deve-ter-cuidado-como-empreendedorismo-de-palco. Acesso em: 07 Set. 2019.

CWK. O que há de verdadeiro no "empreendedorismo de palco"? CWK Coworking, 2016. Disponível em: https://cwk.com.br/o-que-ha-de-verdadeiro-no-empreendedorismo-de-palco/. Acesso em: 07 Set. 2019.

DIAS, L. O que é empreendedorismo de palco? Administradores, 2017. Disponível em: https://administradores.com.br/artigos/o-que-e-empreendedorismo-de-palco. Acesso em: 07 Set. 2019.

EU, CEO. Empreendedorismo de palco. Eu, CEO, 2016. Disponível em: http://www.euceo.com.br/inovacao/empreendedorismo-de-palco/. Acesso em: 07 Set. 2019.

FÁBRICA 3. Não preciso de um coach. Fábrica 3, 2019. Disponível em: http://fabrica3.com.br/nao-preciso-de-um-coach/. Acesso em: 07 Set. 2019.

IDEXO. Eventos de empreendedorismo geram negócios ou apenas likes? Idexo, 2019. Disponível em: https://www.idexo.com.br/eventos-de-empreendedorismo-geram-negocios-ou-apenaslikes/. Acesso em: 07 Set. 2019.

LAMARDO, R. O fim da era do empreendedorismo de palco. Empreender Shopify, 2016. Disponível em: https://empreendershopify.com/2016/09/23/o-fim-da-era-doempreendedorismo-de-palco-repost/. Acesso em: 07 Set. 2019.

LEAL, M. Empreendedorismo não se faz (só) no palco! Rockcontent, 2018. Disponível em: https://comunidade.rockcontent.com/empreendedorismo-nao-se-faz-no-palco/. Acesso em: 07 Set. 2019.

MACHADO, F. Caso Bel Pesce reaviva críticas aos empreendedores de palco. Veja, 2016. Disponível em: https://veja.abril.com.br/economia/caso-bel-pesce-reaviva-criticas-aosempreendedores-de-palco/. Acesso em: 07 Set. 2019.

MEDIUM. O problema não é o empreendedorismo de palco. Medium, 2018. Disponível em: https://medium.com/startup-da-real/o-problema-n\%C3\%A3o-\%C3\%A9-o-empreendedorismode-palco-9cb278bb7d4d. Acesso em: 07 Set. 2019.

MERLADETE, L. Empreendedorismo de palco e de rede social: nem tudo que reluz é ouro. Diário SM, 2018. Disponível em: https://diariosm.com.br/colunistas/tecnologia/empreendedorismo-de-palco-e-de-rede-socialnem-tudo-que-reluz-\%C3\%A9-ouro-1.2090686. Acesso em: 07 Set. 2019.

MIDIORAMA. Empresários vs. Empreendedores de palco. Midiorama, 2016. Disponível em: https://www.midiorama.com/empresarios-vs-empreendedores-de-palco. Acesso em: 07 Set. 2019. 
PAMPLONA, P. Teologia do coaching: a substituta da teologia da prosperidade. Dois dedos de teologia, 2017. Disponível em: https://doisdedosdeteologia.com/teologia-do-coaching-asubstituta-da-teologia-da-prosperidade/. Acesso em: 07 Set. 2019.

PET ADM UFC. Empreendedorismo de palco ou palestra de autoajuda? PET Administração UFC, 2017. Disponível em: http://www.petadm.ufc.br/?p=3233. Acesso em: 07 Set. 2019.

QUEIROZ. S. Empreendedor de palco? Caia fora. Sayonara Queiroz, 2019. Disponível em: https://www.sayonaraqueiroz.com/empreendedor-palco/. Acesso em: 07 Set. 2019.

ROSOLEN, D. Empreendedor hashtag. Draft, 2019. Disponível em: https://projetodraft.com/selecao-draft-empreendedor-hashtag/. Acesso em: 07 Set. 2019.

ROSSI, G. Empreendedores de palco. Entenda como o setor do sonho funciona. Mundo do Marketing, 2016. Disponível em: https://www.mundodomarketing.com.br/artigos/gabrielrossi/36800/empreendedores-de-palco-entenda-como-o-setor-do-sonho-funciona.html. Acesso em: 07 Set. 2019.

SAIGH, E. Cuidado com a indústria do empreendedorismo. Vida de valor, 2016. Disponível em: http://www.vidadevalor.com.br/cuidado-com-a-industria-do-empreendedorismo/. Acesso em: 07 Set. 2019.

SANT'ANA, J. Atenção: empreendedores de palco se disseminam na base da autoajuda. Gazeta do Povo, 2016. Disponível em: https://www.gazetadopovo.com.br/economia/empreenderpme/atencao-empreendedores-de-palco-se-disseminam-na-base-da-autoajudaa2btttvi1nuum70tgcma4vxfr/. Acesso em: 07 Set. 2019.

SANTOS, G. Empreendedorismo Nutella: muito palco e Power Point e pouco suor no balcão. Gui Santos Pro, 2019. Disponível em: http://www.guisantospro.com/empreendedorismonutella/. Acesso em: 07 Set. 2019.

SERASA EXPERIAN. O que é empreendedorismo? Definição e dicas para quem quer ser um! Serasa Experian, 2018. Disponível em: https://empresas.serasaexperian.com.br/blog/o-que-eempreendedorismo-definicao-e-dicas-para-quem-quer-ser-um/. Acesso em: 07 Set. 2019.

SMARTY. Quem pode ensinar sobre empreendedorismo. Smarty, 2017. Disponível em: http://smartytalks.com/pb/empreendedorismo/. Acesso em: 07 Set. 2019.

TASIC, I. Não seja um empreendedor de palco. Pequenas empresas e grandes negócios, 2016. Disponível em: https://revistapegn.globo.com/Colunistas/Igor-Tasic/noticia/2016/10/nao-sejaum-empreendedor-de-palco.html. Acesso em: 07 Set. 2019.

TERCEIRO, I. 6 coisas que você precisa saber antes de sair por aí falando que todo empresário é malvado. Spotniks, 2017. Disponível em: https://spotniks.com/6-coisas-que-voce-precisasaber-antes-de-sair-por-ai-falando-que-todo-empresario-e-malvado/. Acesso em: 07 Set. 2019.

THOMAZIN, R. Sonho x realidade: quando o empreendedor não sabe como vender. Rotina de vendas, 2017. Disponível em: http://www.rotinadevendas.com.br/sonho-X-realidade-quando-oempreendedor-nao-sabe-como-vender/. Acesso em: 07 Set. 2019.

VABO, L. Não perca tempo com empreendedores de palco. B2B Tech, 2016. Disponível em: https://blog.panrotas.com.br/b2btech/2016/11/09/nao-perca-tempo-com-empreendedores-depalco/. Acesso em: 07 Set. 2019.

VIEGAS, R. Chega de empreendedorismo de palco e coaches! Renan Viegas, 2019. Disponível em: https://www.renanviegas.com.br/chega-de-empreendedorismo-de-palco-e-coaches/. Acesso em: 07 Set. 2019.

WOLLHEIM, B. O "empreendedorismo de palco" desvendado. 15 frases com as legendas que nunca são ditas. Draft, 2016. Disponível em: https://projetodraft.com/o-empreendedorismo-depalco-desvendado-15-frases-com-as-legendas-que-nunca-sao-ditas/. Acesso em: 07 Set. 2019. 